\section{The Role of the Precautionary Principle in Water Recycling}

A.I. Schäfer ${ }^{\mathrm{a}^{*}}$ and S. Beder ${ }^{\mathrm{b}}$

${ }^{a}$ Environmental Engineering, The University of Wollongong, NSW, 2522, Australia. Tel: +61 24221 3385, Fax +61 2 4221 4738, E-mail: schaefer@uow.edu.au

${ }^{\mathrm{b}}$ Social Sciences, Media and Communication, The University of Wollongong, NSW, 2522, Australia. Tel: +61 24221 4063, Fax +61 24221 3452, E-mail: sharonb@uow.edu.au
* Corresponding author.

\section{Abstract}

In an engineering context the precautionary principle is often perceived as an excuse to do nothing or a substantial barrier to technical progress. The precautionary principle requires that remedial measures be taken in situations of scientific uncertainty where evidence of harm cannot be proven but potential damage to human or environmental health is significant.

In this paper the scope of the precautionary principle in water recycling is discussed. It is clear that uncertainties and risks exist in many areas of water recycling. Those risks are closely linked to the risks of sewage discharge.

Hence water recycling has two main areas of concern (i) the dilemma that minimising potential environmental harm by reducing effluent discharge may increase potential harm through reducing the water flow in receiving waters and (ii) the consequences of using recycled water of varying quality for a number of applications.

The precautionary principle can be regarded as an opportunity to improve water recycling practice and in fact increase the scope of ecologically sustainable water recycling. Hence the precautionary principle has an important role to play as a guide in decision making and in dealing with the vast number of risks and uncertainties in water recycling.

Keywords: Precautionary principle, water recycling, uncertainties, risks, environmental impact

\section{Introduction}

Water recycling is a multidisciplinary and often controversial topic. Public resistance has been identified as a key barrier to water recycling even though it can be an environmentally sound and technologically feasible solution to problems of heavy water usage and scarcity. Lack of trust in water authorities, as well as fear of the unknown, appear to be drivers in some public responses.

The uncertainties involved in water recycling are often of a technical nature and concerned with questions of contamination, adequate treatment and usage of recycled water. They provide the incentive to do more research, more thoroughly monitor quality and to more tightly control recycling processes. However the issue of water recycling is not merely a technological one. The concept of "toilet to tap" is somewhat emotionally charged; a response that is understandable given the breadth of human experience with disease resulting from drinking water contaminated with sewage. Similarly the potential loss of fertility or other hum from functions that could result from the presence of an ever alarm. Water recycling also raises many ethical $i$ uncertainties and passions surrounding these questions and issues. The precautionary principle offers some guidance in this.

Andorno [1] argues that the precautionary principle (PP) is best understood in terms of 'prudence'. He refers to the classical meaning of prudence: the "ability to discern the most suitable course of action" or "practical wisdom". In the context of water recycling, the precautionary principle guides managers as to how to make prudent or wise decisions that consider actions in the context of the total water cycle. Decisions as to whether to discharge marginally treated sewage to con to the to sewage to a quality ince application in between, are non-trivial. They are often driven by economics, political agendas or technical heroism. This paper will explain the precautionary principle and outline the application of this principle to water recycling decision making and management.

1.1. Definition and status of the precautionary principle

The precautionary principle (PP) is central to achieving sustainable development. It deals with situations where there is scientific evidence that serious harm might result from a proposed action but there is no certainty that it will. The precautionary principle requires that in such situations action be taken to avoid or mitigate the potential harm, even before there is scientific proof that it action be tak occur.

The use of precaution has a long history and one can argue that John Snow exercised precaution when he removed the handle from a London water pump in 1854 because he suspected that the water was causing people to get cholera, even though the causal link between cholera and contaminated water had not been proven at that time. The measure succeeded in saving many lives [2].

The precautionary principle, as a principle, dates back to the 1970s, when it was incorporated into German and Swedish environmental policy. During the 1980s it was integrated into a number of international treaties including the North Sea Treaties [3]. It achieved widespread recognition after it was incorporated into the Rio Declaration on Environment and Development decided at the 1992 UN Conference on Environment and Development (UNCED) in Rio. The Declaration states:

"Where there are threats of serious or irreversible damage, lack of full scientific

certainty shall not be used as a reason for postponing cost-effective measures to

prevent environmental degradation"

Today the precautionary principle is "a central plank" of European Community policy [4] However, it is controversial in the US where corporate interests have succeeded in spreading confusion about what the principle means and implies. Opponents argue that the precautionary principle is unscientific; can be triggered by irrational concerns; that it aims at an unrealistic goal of zero risk and that it will result in the banning of useful chemicals and preventing technological innovation [5].

In actual fact, as this paper will show, the precautionary principle cannot be applied without scientific evidence of harm. The Canadian government [5] points out that "sound scientific information and its evaluation must be the basis" for applying the PP and, in deciding whethe scientific evidence is sound, "decision makers should give particular weight... to peer-reviewed science”.

Nor does the PP aim to reduce risk to zero but rather to mitigate likely harm. The measures to be adopted to achieve this are not dictated by the precautionary principle and there is no requirement on the part of the PP to ban anything, although decisionmakers may decide that a ban may be appropriate in certain circumstances. Adorno [1] notes that PP is certainly not a "decision making algorithm" telling managers how to choose between pre-existing solutions, it is a guide as to when precaution needs to be exercised.

Andorno further emphasises that the precautionary principle does not conflict with technological innovation, but requires a new approach - an approach that incorporates quality of life, cleaner and safer technologies. What the PP does is to redirect innovation into more humane and environmentally sound directions.

1.2. When to apply the precautionary principle

The precautionary principle helps managers and policy-makers to make decisions and pass laws in situations of scientific uncertainty. It is based on the folk wisdom of "better safe than sorry" and is only invoked when there is scientific evidence that there is a high risk that taking an action will result in serious harm. In such circumstances, the precautionary principle requires that some positive action, beyond "wait and see" or further research, be taken to mitigate the likely harm. The 
measures to be taken are not prescribed by the PP. The principle is regarded as a duty rather than an intention and needs to be applied whenever there are "reasonable grounds for concern” [6].

Due to the relatively open definition of the precautionary principle, Andorno [1] has specified a number of conditions under which the precautionary principle is to be applied. Those conditions are summarized in Table 1.

Table 1 Conditions for the application of the precautionary principle [1]

\begin{tabular}{|l|l|l|l|}
\hline Condition & \multicolumn{1}{|c|}{ Summary } & \multicolumn{1}{c|}{ Precaution } & \multicolumn{1}{|c|}{ Water Recycling Example } \\
\hline Uncertainty of risk & $\begin{array}{l}\text { Existence of risk cannot be } \\
\text { proven }\end{array}$ & $\begin{array}{l}\text { Response to situations of } \\
\text { potential risk }\end{array}$ & $\begin{array}{l}\text { Water that contains persistent } \\
\text { organic pollutants or prions is } \\
\text { applied to pastures and effect on } \\
\text { food chain is not clear }\end{array}$ \\
\hline $\begin{array}{l}\text { Scientific } \\
\text { assessment of likely } \\
\text { harm }\end{array}$ & $\begin{array}{l}\text { Good reason to believe } \\
\text { that there might be } \\
\text { harmful effects }\end{array}$ & $\begin{array}{l}\text { Definition and evaluation of } \\
\text { uncertainties by scientific } \\
\text { experts }\end{array}$ & $\begin{array}{l}\text { Determination of concentration } \\
\text { and effect of such pollutants on } \\
\text { food chain through monitoring } \\
\text { and calculations }\end{array}$ \\
\hline $\begin{array}{l}\text { Serious or } \\
\text { irreversible damage } \\
\text { (short or long term) }\end{array}$ & $\begin{array}{l}\text { Likelihood of serious or } \\
\text { irreversible effects on life } \\
\text { and health of individuals, } \\
\text { vital natural resources, } \\
\text { species preservation, } \\
\text { climate, ecosystem balance }\end{array}$ & $\begin{array}{l}\text { Determination of a threshold } \\
\text { of non-negligible damage }\end{array}$ & $\begin{array}{l}\text { Accumulation of persistent } \\
\text { pollutants has long term fertility } \\
\text { effects on a number of species } \\
\text { (which are both serious and } \\
\text { irreversible) }\end{array}$ \\
\hline $\begin{array}{l}\text { Proportionality of } \\
\text { measures }\end{array}$ & $\begin{array}{l}\text { Measures taken to avoid } \\
\text { likely harm should take } \\
\text { impact on society into } \\
\text { account }\end{array}$ & $\begin{array}{l}\text { Identification of socio- } \\
\text { economic sacrifices required } \\
\text { to adapt the precaution, } \\
\text { careful evaluation of } \\
\text { precautionary measures } \\
\text { available and active review }\end{array}$ & $\begin{array}{l}\text { Consideration of effect of } \\
\text { extended drought on farmers }\end{array}$ \\
\hline $\begin{array}{l}\text { Shifting burden of } \\
\text { proof }\end{array}$ & $\begin{array}{l}\text { Those who may cause } \\
\text { serious damage show that } \\
\text { it is unlikely }\end{array}$ & $\begin{array}{l}\text { Hazard creators assume costs } \\
\text { of risk assessment; proof of } \\
\text { zero risk is not realistic }\end{array}$ & $\begin{array}{l}\text { Water recycling authority is } \\
\text { required to show that the } \\
\text { possible risk has been } \\
\text { thoroughly investigated }\end{array}$ \\
\hline
\end{tabular}

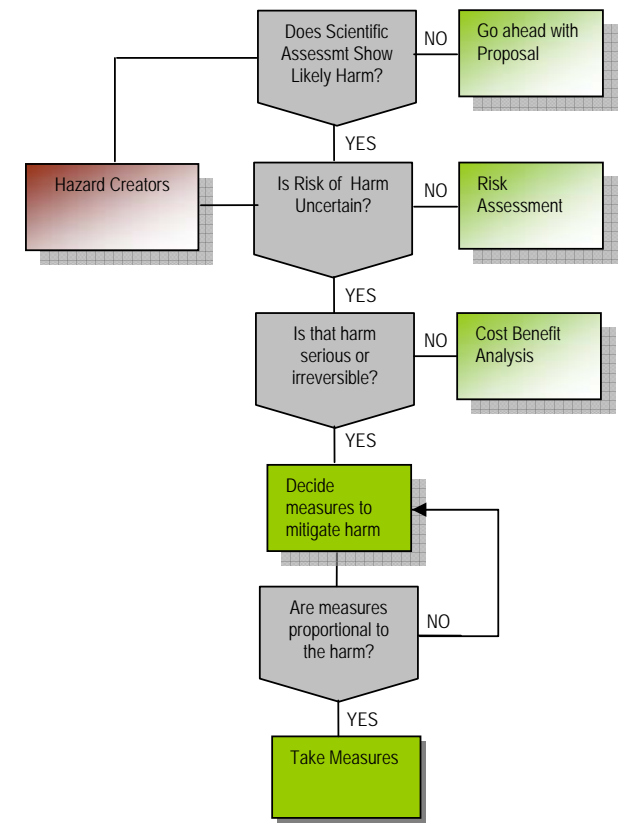

Figure 1 Flow chart for the application of the precautionary approach

1.3. Legal status of the precautionary principle

Today the precautionary principle is well established in Europe and is evolving into a principle of international law. In recent times it has been included in almost all treaties and international policy documents [1, 6]. As Andorno [1] summarises in great detail, the PP has been inspiring court judgements on a number of occasions in international law (a mad cow disease case being an example) and has been adopted into environmental law in many countries. On a global level international courts are still reluctant to accept the principle as a legal or a general principle, but it is accepted as an approach. Courts are at this point expected to be guided by it in similar ways as they are guided by the principle of sustainable development.

In terms of legal implications for water recycling this raises many questions, but one would expect that courts would request evidence of due diligence with regards to dealing with uncertainties and possible risks. In water recycling, with an increasing amount of scientific data and literature becoming available, the evidence of likely but uncertain harm is becoming more difficult to ignore.

1.4. Current trends in water recycling

Wastewater should be considered as a resource, not a waste, where the recycled water is a valuable product [7]. However, water recycling impacts on the environment and health both negatively and positively. Within the field of "sanitary engineering" priority has traditionally been negatively and positively. Withen to human health effects and hence the removal of sewage (unsafe water) and the provision of given to human health effects and hence the removal of sewage (unsafe water) and the provision of
clean water for human consumption [8]. This traditional approach has led to an enormous and vastly irreversible infrastructure of water supply and sewage discharge (in Sydney alone about $20000 \mathrm{~km}$ of pipes are providing water and $20000 \mathrm{~km}$ of pipes are recovering sewage). 
The availability of water has led to an expectation of unlimited and cheap (if not free) access to this resource and a subsequent development of a culture of overconsumption. Population and economic growth and a change in weather patterns, as well as the increasingly apparent environmental impacts of depleted water resources, have led to a political awareness that is now more favourable to water conservation and recycling.

For political reasons high targets are being set for water recycling and vast resources are being assigned to the problem "water" (at least in Australia where currently the first national research priority is water - a critical resource). Yet the tools available for sound decision-making, in terms of priority is water - a critical resource). Yet the tools available for sound decision-making, in terms of appropriate technology for required water applications, are scarce and suitable clients of the recycled water product difficult to come by. Energy intensive solutions, such as desalination or long distance transport of water, continue to be expensive options, but remain on the agenda because of the perceived "risks" or uncertainties in using a problematic resource: sewage.

Globally the full spectrum of water recycling technology has been applied. This includes direct potable reuse in Namibia; indirect potable reuse in Singapore and California; industrial and agricultural uses [9]; and inevitably, unplanned recycling of effluent into the water cycle where rivers and streams serve as both water supply and sewage recipients, often covering many thousands of kilometres and several countries [10]. Technology choices are vast and depend on the thousands of kilometres and several countries [10]. Technology choices are vast and depend on the source of the wastewater [11], where greywater, yellow water (urine), blackwater and stormwater
are categories in the municipal (non-industrial) wastewater classification. Figure 2 illustrates a wastewater cycle considering some of those categories, possible recycling options and the required input of energy and chemicals, as well as the output of chemical waste, sludge and solids and gas emissions in such a cycle.

Figure 2 Water, wastewater and stormwater cycle with recycling options

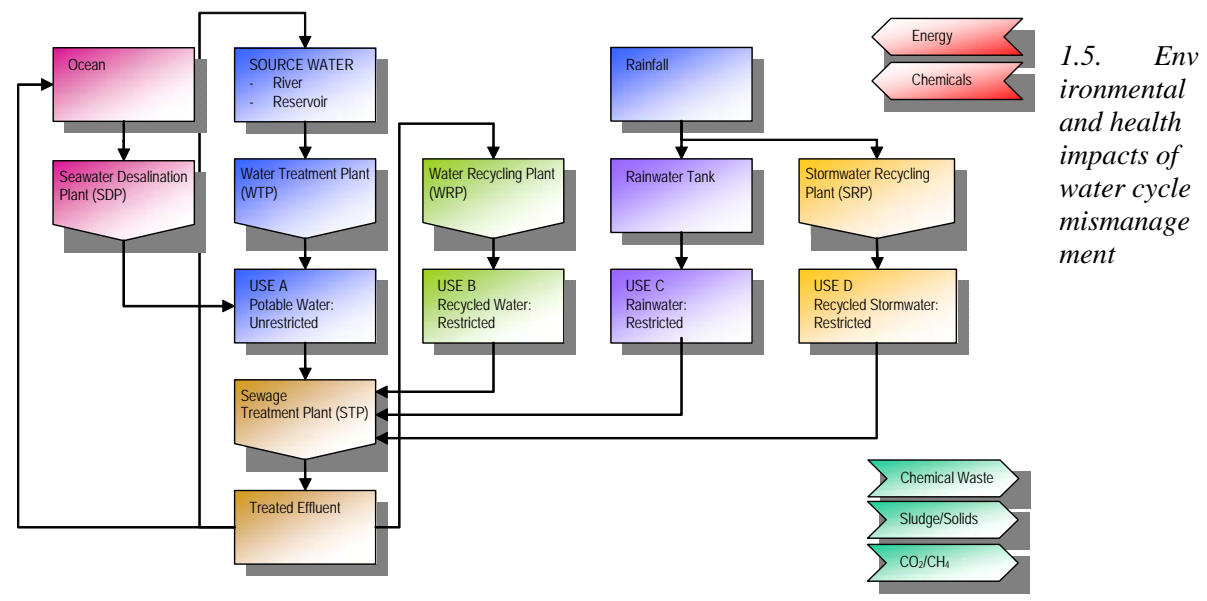

Tsagarakis [7] expects that consumers will one day willingly pay a price for recycled water close to that of freshwater as "not only do they buy recycled water, but a better environment future as well, for the generations to come". The ultimate driver for this price adjustment is seen as being a steadily increasing demand for recycled water, limited only by its supply. The environmental benefits of water reuse have been outlined by Anderson [9].

Implications of "water cycle mismanagement" are not always apparent and measurable but can result in the pollution of beaches near ocean outfalls, depletion and pollution of rivers and streams, immediate illness resulting from water contamination, or chronic effects of pollution on wildlife [12]. While reports of such incidents have contributed to raising public concern about water recycling, scientific evidence of the impacts of recycling is often difficult to obtain leaving a vast array of uncertainties too difficult to resolve for individual authorities. In the next section of this paper such uncertainties are investigated.

\section{Uncertainties in water recycling}

\subsection{Uncertainty of risk}

A key element of the precautionary principle is the uncertainty of risk [1]. While many risks in water recycling are well established, such as the likelihood of pathogenic contamination of treated effluents, some are unknown, such as the long term exposure of wildlife, cattle or humans to persistent organic pollutants with more subtle and less immediate effects, from cancer to endocrine disruption. However, many authorities remain in the modus operandi of doing nothing (or in fact claiming that there is no issue) with regards to such compounds until the scientific evidence of harm - a tangible toxicology result - has been established. In consequence the only response to these threats is research into the toxicological effects of persistent pollutants. The burden of proof for action to be taken remains, in the current system, clearly with the defenders of environment and action to be taken remains, in the current system, clearly with the defendews
health. As a result community trust in these authorities is understandably low.

The European Commission produced a Communication on the PP in 2000 which states that the PP should be applied "where the possibility of harmful effects on health or the environment has been identified and preliminary scientific evaluation, based on the available data, proves inconclusive for assessing the level of risk" [1]. This points to a number of water recycling issues, some of which will be placed into context below. A flowchart of possible, though not all, risks in water recycling is shown in Figure 3.

It should be noted here that our expectation that further research will reduce (or eliminate) uncertainties may be unrealistic. In fact further research may lead to the discovery of additional uncertainties and complexities [13]. For water recycling it is well known that research into new contaminants, with the aid of more and more sophisticated analytical tools, can find out whether harmful compounds are present but this only raises more uncertainties surrounding their possible effects and available remedies.

Van der Sluijs [13] claims that one way that authorities cope with unwelcome uncertainty that does not fit with an authoritative approach is "strategic hiding of uncertainty". This may be why it has taken so long for water authorities to recognise persistent pollutants - particularly since it is difficult to know how to deal with them. An alternative approach is to be open about the uncertainties involved and strive "for transparency of the various positions and learn to live with ambiguity and pluralism in risk assessment". Chee [14] emphasises similar approaches integrating "participation, explicit treatment of uncertainty and transparent decision-making processes" as opposed to the traditional cost-benefit analysis. 


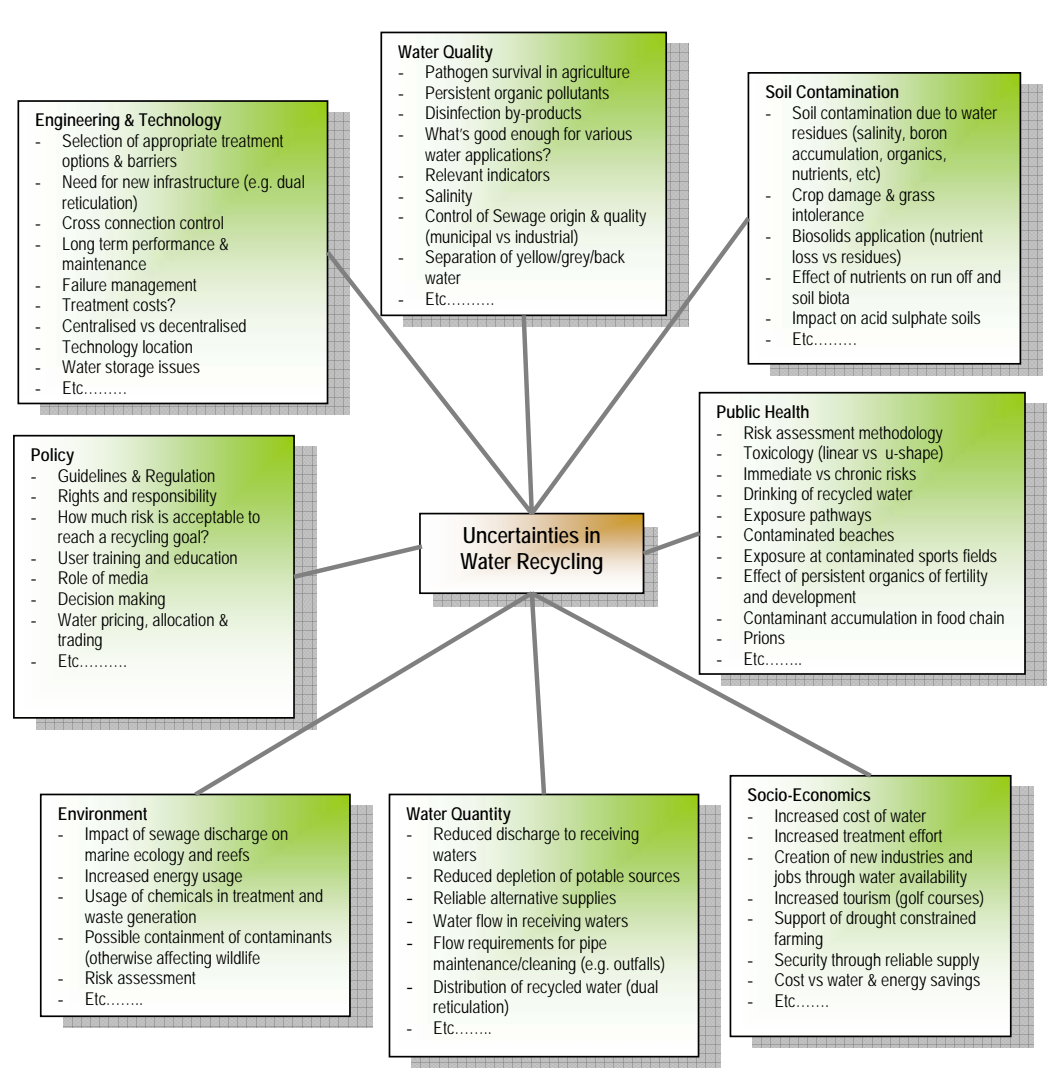

Figure 3 Possible known and anticipated risks or uncertainties in water recycling

The uncertainties outlined in Figure 3 are categorised into some dominant areas which illustrate the complexity of issues and result in inevitable difficulties for decision making. Weighing up and quantifying possible impacts is dependent on location as well as circumstances, and hence requires significant value judgements.

2.2. Water quantity issues

The water cycle is no longer quite the way it is presented in common textbooks. Natural waterways have been modified extensively and human activities have deviated many water courses [9]. In many cases this has led to a near complete depletion of water quantity, competition over [9]. In many cases this has led to a near complete depletion of water quantity, competition over
freshwater allocation and a dominance of 'discharged effluent' in waterways. According to Anderson [9] water conservation, reuse and recycling can effectively counteract such depletion.

As watersheds are developed and utilised extensively not only water quantity but also quality starts playing an important role. This is due to the passage of water through intense polluting activities [15]. While some of this pollution is a result of planned urban activities, the uncontrolled events of runoff or treatment unreliability are also important factors. It is unknown if wate recycling in fact contributes to the rehabilitation of watersheds or causes further stress. Such investigations require further studies and are inevitably complex in nature.
2.3. Water quality issues

Material cycles apply to contaminants as well as natural materials such as nutrients. As for the water cycle, human activity has distorted many natural material cycles [15] and introduced many new contaminants to be considered. Contaminants discharged to the environment enter the water cycle and unless diluted to levels lower than current detection limits or effectively degraded, will accumulate and can eventually be found in 'pristine' water sources [16]. For example Heberer [17] has carried out a study that detected selected pharmaceutically active compounds in Berlin's tap water and detected numerous wastewater contaminants.

The topic of persistent organic pollutants is much debated and presents a very important opportunity to adapt a precautionary approach as is further elaborated in section 3.2. Heberer et al. [18] indicate that the presence of such compounds in water resources even at low concentrations is not desirable with regards to the precautionary principle. Treatment and water recycling will impact on the distribution of such material loads. Beck [15] has demonstrated the impact of sewage in an urban environment before and after installation of comprehensive treatment. The extent to which treatment will reduce the concentrations of persistent organic pollutions depends on the nature of the contaminants and the effectiveness of the treatment plant. For example, Carballa et al. [19] the contaminants and the effectiveness of the treatment plant. For example, Carballa et al. [19]
have investigated the removal of several groups of compounds in wastewater treatment plants and found variations from $20-90 \%$. Anderson [9] expects a better downstream water quality if water reclamation is implemented.

2.4. Environmental impacts

The environmental impact of water recycling, compared with the more traditional approach of water extraction and sewage discharge, is difficult to establish as Jeffrey et al. [20] have demonstrated in an attempt to model water recycling options. Palme et al. [21] have developed an iterative method to establish sustainable development indicators (EDI) for wastewater systems (with a focus on sludge handling) that incorporates the precautionary principle as well as numerous environmental tools (such as life cycle assessment), economic analysis and risk \& uncertainty assessment. The definition of boundaries is important in such attempts, which, for water recycling, may be a limiting factor, particularly when a total water cycle approach is required. However, definite advantages are likely to be the reduction of freshwater usage, reduction in pollutant discharge and better downstream water quality $[9,22]$. Indeed, the environmental impact of wastewater discharge is a driver in countries with plentiful water resources [23] whereas drought and water restrictions are a recycling motivation in other circumstances.

\section{Opportunities for the precautionary approach in water recycling}

3.1. Public perception and community participation

Public participation has long been identified as a major stepping stone in water recycling implementation. Integrating the human dimension with technology remains a challenge and can take many shapes and form. For example Beck [15] envisages a process of 'adaptive community take many shapes and form. For example Beck [15] envisages a proce

Fear plays an important role in public response. "Fear is connected to the presentiment of
Fing whe technology may also need to learn from human need. radical unknown dangers" [13]. As was noted above, issues related to water recycled can be highly emotional, in particular when male sperm counts, extinction of threatened species or images of drinking excrement come into play. It is important to note that the precautionary principle is not an excuse to give way to unjustified fears. As the EC Communication [4] notes, there has to be plausible scientific evidence of the likelihood of harm before use of the precautionary principle is triggered. While this certainly does not inhibit the thorough investigation of fears surounding water recycling common in society, the existence of those fears does not, in itself, justify precautionary measures. Once potentially negative effects have been identified, the possible risks have to be
scientifically assessed. The precautionary principle is applicable only when that scientific 
assessment finds that the risk of harm is significant but there is insufficient data to quantify the risks so a risk assessment is not feasible. Unless there is a scientifically credible level of risk, application of the precautionary principle is a misuse of the principle [24]. Taking fears seriously and providing solid data that can mitigate the experienced fear is likely an important step in gaining trust of the public.

The EC Communication [4] notes that evaluating the level of harm that an activity poses it is necessary to know whether a "desired level of protection for the environment or a population group could be jeopardised". Although the evaluation of likely harm is a scientific activity, the desired could be jeopardised". Although the evaluation of likely harm is a scientific activity, the desired
level of protection is a political decision that requires public participation. For this reason the EC advices that is necessary to "involve all interested parties at the earliest possible stage".

Andorno [1] describes the greatest merit of the precautionary principle as the fact that it has succeeded in reflecting the "current public concern about the need to favour the protection of the public health and the environment over short term commercial interests at the time of choosing among different technological alternatives". This clearly challenges assumptions behind costbenefit analysis, which is so often the driver of engineering solutions [25].

These statements show how important public participation is in implementing the precautionary principle with respect to water recycling. Firstly, public concerns are important in identifying potential risks. Secondly, the community has a right to decide the level of environmental and health protection they will live with. Thirdly, measures taken to mitigate likely harm need to be evaluated to ensure that the impact of the measures are not worse than the impact of the harm they are seeking to mitigate. For all these reasons, it is not enough to merely offer the public a choice of a limited range of 'solutions' at the end of the decision-making process [26]. Innovative approaches in water recycling involve the public from an early stage so people can take part in developing suitable options. Such approaches can indeed be observed in a limited number of successful recycling strategies.

\subsection{Persistent organic pollutants}

Many categories of potentially harmful pollutants from natural or human activity are not included in current water recycling legislation, such as persistent organic pollutants, trace contaminants, emerging pollutants, and endocrine disrupting chemicals. While the issue has recently reached a high level of controversy and research activity, the concept is not new as Colborn emphasises in her comprehensive review [27].

Heberer [16] has illustrated possible sources and pathways of pharmaceuticals in the aquatic environment. Pathways link excretion with sewage treatment plants, land application of solids and drinking water resources. His model does not include all possible pathways, which in coastal countries such as Australia would also include bioaccumulation, in particular in seafood, and countries such as Australia would also include bioaccumulation, in particular in seafood, and
subsequent exposure [28]. Sanderson et al. [29] have ranked several thousands of organic compounds, mostly pharmaceuticals, into hazard categories for the model organisms (notably not humans) with the aim of prioritising compounds for further risk assessment investments.

The treatment of such contaminants with traditional risk assessment methodology is unrealistic because of scientific uncertainties. As Daughton [30] points out, the dose response curves of low concentration contaminants varies significantly from expectations, in particular when (a) con mixtures of con criticises the curcent "reactive" approach to pollutants directly and welcomes the use of a "futuring" approach in this area. Here the anticipation of problems prior to the need for remediation is emphasised, futuring meaning the "formulation of challenging questions regarding adverse scenarios".

Applied to water recycling (and the abundance of various pollutants) questions arise as to what happens to these compounds - some of them being natural - during chlorination and during further treatment. For example, formation of effluent disinfection by-products that are highly carcinogenic or potent with regards to other effects (such as NDMA) is to date poorly understood. Degradation in advanced oxidation processes or natural photochemical degradation is also uncertain? If treated and contained what happens to the waste stream? What happens if contaminants are introduced into the food chain where a further chain of natural (biological or photochemical) degradation into further and possibly more potent byproducts will take place? What are the cumulative effects and effects of mixtures? What are half lifes of compounds? We cannot answer these questions and it is questionable if these uncertainties can ever be resolved to a satisfactory level.

\subsection{Solids management}

Land application of sewage sludge is another contentious issue for water recycling. Sludge quality issues are concerned with heavy metals, a number of organic substances and specific compounds such as brominated flame retardants [21]. Bengttson and Tillman [31] have compared the application of the precautionary and proof-first frameworks to the land application of sewage sludge as fertiliser. There are tradeoffs between the risks involved and the benefits of recycling nutrients, which a priori are environmentally sustainable; the economic benefits to farmers and councils; and the relatively high costs of other sludge handing alternatives. A vast number of methods for sludge treatment and disposal options were investigated and included in their discussion, but the process was regarded as lacking "shared understandings on the level of principles". The process involves uncertainties (unknown hazardous substances and pathogens in the sludge), and hence requires value judgements as to what level of risk is acceptable to achieve the goal of nutrient recycling. Ultimately, who is taking responsibility and potential blame for the consequences?

\section{Conclusions}

With the levels of uncertainty described above, regarding the potential health and environmental impacts related to choosing options in water recycling (including the choice not to recycle), decisions have to be based on a diverse knowledge base ranging from "well-established knowledge to judgments, educated guesses and tentative assumptions" [13]. In other words, decisions need to be made before uncertainties are resolved, and this may result in potentially high "error costs". Past errors have resulted from accidental release of chemicals [27] or, in a more direct link to water recycling, the land application of biosolids.

The precautionary principle has been examined in the context of water recycling, where many uncertainties have been shown to exist. For the water recycling practitioner or decision maker the precautionary principle should be used as an integrative part of planning, so that possible problems can be anticipated and dealt with wisely despite the uncertainties surrounding them. Lack of relevant legislation in water recycling [23] and the current efforts to establish such legislation worldwide open an important opportunity for the precautionary principle to be considered and applied.

Adopting a precautionary approach requires a high level of transparency in political decisions where public or environmental risk is involved. Such transparency, combined with public participation will no doubt lead to a higher level of trust and is more likely to lead to the adoption of participation will no doubt lead to a high

To close with the words of one of this world's greatest thinkers;

"The significant problems we face cannot be solved at the same level of thinking we had when we created them" (Albert Einstein).

Our approach to the global water crisis requires new thinking, a different mindset to the one that has generated current problems. It is up to us to make this shift in thinking so that we can solve those problems. More engineering alone, as comfortable as most of us would be with this approach, is unlikely to achieve breakthroughs in a world whose complexity we have limited ability to is unlikely to achieve breakthroughs in a world whose complexity we have limited ability to
perceive. Who knows what would happen if we were to replace our need to understand and control with a sense of wonder and respect? 


\section{References}

[1] R. Andorno, The precautionary principle: a new legal standard for a technological age, Journal of International Biotechnology Law 1 (2004), 11-19.

[2] European Environment Agency, Late lessons from early warnings: the precautionary principle 18962000, (2001), Copenhagen.

[3] National Research Ethical Committees, The Precautionary Principle: Between Research and Politics, NENT (1998), Oslo.

[4] Commission of the European Communities, Communication from the Commission on the precautionary principle, 1 (2000), Brussels.

[5] Environment Canada, A Canadian Perspective on the Precautionary Approach/Principle, (2001),

[6] R. Harding, E. Fisher (eds.), Perspectives on the Precautionary Principle (The Federation Press, Sydney, 1999).

[7] K. P. Tsagarakis, Recycled water valuation as a corollary of the 2000/60/EC water framework directive, Agricultural Water Management (in press) (2004),

[8] S. Beder, Technological Paradigms: The Case of Sewerage Engineering, Technology Studies 4 (2) (1997), 167-188.

[9] J. M. Anderson, The environmental benefits of water recycling and reuse, Water Science and Technology: Water Supply 3 (4) (2003), 1-10.

[10] T. Wintgens, T. Melin, A. Schäfer, S. Khan, M. Muston, D. Bixio, C. Thoeye, The role of membrane processes in municipal wastewater reclamation and reuse, Desalination in press (2005),

[11] B. Jefferson, A. Laine, S. Parsons, T. Stephenson, S. Judd, Technologies for domestic wastewater recycling, Urban Water 1 (1999), 285-292.

[12] S. Beder, The New Engineer: Management and Professional Responsibility in a Changing World MacMillan: Melbourne, 1998.

[13] J. van der Sluijs, Quicksandy knowledge bases: coping with mixtures of knowledge and ignorance in environmental assessment, UPEM (2004), 1-8

[14] Y. E. Chee, An ecological perspective on the valuation of ecosystem services, Biological Conservation 120 (2004), 549-565.

[15] M. B. Beck, Vulnerability of water quality in intensively developing urban watersheds, Environmental Modelling \& Software 20 (2005), 381-400.

[16] T. Heberer, Occurrence, fate, and removal of pharmaceutical residues in the aquatic environment: a T. Heberer, Occurrence, fate, and removal of pharmaceutical residues
review of recent research data, Toxicology Letters 131 (2002), 5-17.

[17] T. Heberer, Tracking persistent pharmaceutical residues from municipal sewage to drinking water, Journal of Hydrology 266 (3-4) (2002), 175-189.

[18] T. Heberer, D. Feldmann, K. Reddersen, H. Altmann, T. Zimmermann, Production of drinking water from highly contaminanted surface waters: removal of organic, inorganic, and microbial contaminants applying mobile membrane filtration units., acta Hydrochimica Hydrobiologica 30 contaminants applying mobile membrane filtration units., acta Hydrochimica Hydrobiologica
(1) (2002), 24-33.

[19] M. Carballa, F. Omil, J. M. Lema, M. Llompart, C. Garcia-Jares, I. Rodriguez, M. Gomez, T. Ternes, Behavior of pharmaceuticals, cosmetics and hormones in a sewage treatment plant, Water Research 38 (2004), 2918-2926.

[20] P. Jeffrey, R. Seaton, S. Parsons, T. Stephenson, B. Jefferson, Exploring water recycling options for urban environments: a multi-criteria modelling approach, Urban Water 1 (1999), 187-200.

[21] U. Palme, M. Lundin, A.-M. Tillman, S. Molander, Sustainable development indicators for wastewater systems - researchers and indicator users in a co-operative case study, Resources,

[22] T. Asano (ed.) Wastewater Reclamation and Reuse (Technomic Publishing Co., Inc., Lancaster,

[23] A. N. Angelakis, L. Bontoux, V. Lazarova, Challenges and prospectives for water recycling and reuse in EU countries, Water Science and Technology: Water Supply 3 (4) (2003), 59-68.

[24] R. Nilsson, Commentary: Control of chemicals in Sweden: an example of misuse of the

“precautionary principle”, Ecotoxicology and Environmental Safety 57 (2004), 107-117.

[25] S. Beder, The Environment Goes to Market, Democracy and Nature 3 (3) (1997), 90-106.

[26] S. Beder, Public Participation or Public Relations?, in Technology and Public Participation ed. B.

Martin) Science and Technology Studies: University of Wollongong1999, 169-189.

[27] T. Colborn, D. Dumanoski, J. P. Myers, Our stolen future Abacus: London, UK, 1997.

[28] S. Beder, Toxic Fish and Sewer Surfing Allen \& Unwin: Sydney, 1989.
[29] H. Sanderson, D. J. Johnson, T. Reitsma, R. A. Brain, C. J. Wilson, K. R. Solomon, Ranking an prioritization of environmental risks of pharmaceuticals in surface waters, Regulatory Toxicology and Pharmacology 39 (2004), 158-183.

[30] C. G. Daughton, Non-regulated water contaminants: emerging research, Environmental Impact Assessment Review 24 (2004), 711-732.

[31] M. Bengtsson, A.-M. Tillman, Actors and interpretations in an environmental controversy: the Swedish debate on sewage sludge use in agriculture, Resources, Conservation and Recycling 42 (2004), 65-82 